\title{
Havayolu İşletmelerinde İki Aşamalı Veri Zarflama Analizi İle Etkinlik Ölçümü
}

\section{Veysi ASKER ${ }^{1}$}

\section{$\ddot{\mathrm{O} z}$}

$\mathrm{Bu}$ çalışmanın amacı, dünyanın çeşitli yerlerinde faaliyet gösteren ve farklı iş modelini uygulayan havayolu işletmelerinin operasyonel ve finansal açıdan etkinliklerinin karşılaşıırılmasıdır. Bu doğtultuda geleneksel iş modelini uygulayan 19 ve düşük maliyetli iş modelini uygulayan 17 havayolu işletmesinin 2013-2018 dönemine ait etkinlik ölçümü iki aşamalı veri zarflama analizi tekniği ile gerçekleştirilmiştir. Araştırmanın sonucunda, operasyonel açıdan geleneksel iş modelini uygulayan havayolu işletmelerinin daha etkin olduğu, finansal açıdan ise düşük maliyetli iş modelini uygulayan havayolu işletmelerinin daha etkin olduğu tespit edilmiştir. Bununla birlikte her iki grup açısından da operasyonel etkinlik değerlerinin finansal etkinlik değerlerine göre daha yüksek olduğu görülmüştür. Operasyonel açıdan etkinlik ölçümü sonucunda geleneksel havayolu işletmeleri içerisinde 5 havayolu işletmesinin, düşük maliyetli havayolu işletmeleri içerisinde ise 4 havayolu işletmesinin tüm dönem boyunca etkin çıktığı tespit edilmiştir. Finansal açıdan ise tüm dönem boyunca etkin olan hiçbir işletmeye rastlanmamıştır.

Anabtar Kelimeler: Etkinlik, Verimlilik, İki Aşamalı Veri Zarflama Analizi, Düşük Maliyetli Havayolu İşletmeleri, Geleneksel Havayolu İşletmeleri

\section{Measurement of Efficiency with Two-Stage Data Envelopment Analysis in Airline Companies}

\begin{abstract}
The purpose of this study is to compare the operational and financial efficiency of airline companies operating in various parts of the world and applying different business models. Accordingly, the efficiency measurement of 19 airline companies applying the traditional business model and 17 airline companies implementing the low-cost business model for the 2013-2018 period was performed with a two-stage data envelopment analysis technique. As a result of the research, it has been determined that airline companies applying the traditional business model are more efficient in terms of operation, and that airline companies applying the low-cost business model are more effective financially. However, it was observed that the operational efficiency values for both groups were higher than the financial efficiency values. As a result of the operational efficiency measurement, it was determined that 5 airline companies among traditional airline companies and 4 airline companies among low-cost airline companies were effective throughout the entire period. In financial terms, no companies were encountered that was active during the entire period.
\end{abstract}

Key Words: Efficiency, Productivity, Two-Step Data Envelopment Analysis, Low Cost Airline Companies, Traditional Airline Companies

Attf İçin / Please Cite As:

Asker, V. (2021). Havayolu işletmelerinde iki aşamalı veri zarflama analizi ile etkinlik ölçümü. Manas Sosyal Arassturmalar Dergisi, 10(4), 2373-2385.

Geliş Tarihi / Received Date: 16.08.2020

Kabul Tarihi / Accepted Date: 03.06.2021

\footnotetext{
1 Arş. Gör. Dr. - Diyarbakır Dicle Üniversitesi Sivil Havacılık Yüksek Okulu, veysi.asker@dicle.edu.tr

(i) ORCID: 0000-0002-8969-7822
} 


\section{Giriş}

Bölgelerin, ülkelerin ve şehirlerin gelişiminde büyük rol oynayan hava taşımacillğı sektörünün ekonomik, sosyal ve kültürel açıdan birçok faydası bulunmaktadır. Teknolojinin gelişmesiyle birlikte mesafelerin kısaldığı ve etkileşimin arttığ1 günümüzde havayolu taşımacilı̆ııın önemi daha da artmıştır. Hava taşımacilığı sektörü, ticari açıdan ilk kullanıldığı dönemlerde sıkı düzenlemelere tabi olmasından dolayı kayda değer bir gelişim gösterememiştir. Sonraki dönemlerde teknolojinin gelişmesine bağlı olarak ülkelerin hava taşımacilı̆̆ındaki faydaları keşfetmesiyle birlikte sektörün gelişmesine engel olan yasalar tekrar gözden geçirilerek yeniden düzenlenmiştir. Bu düzenlemeler sonucunda bilet fiyatlarında meydana gelen indirimler insanlar açısından havayolu taşımacilğ̆ının daha ulaşılabilir olmasına neden olmuştur. $\mathrm{Bu}$ durum havayolu taşımacıllğı sektörünün büyümesine ve global bir sektöre dönüşmesinde öncü rol oynamişır.

Son y1llarda hava taşımacilığı sektöründe yaşanan serbestleşme hareketi ile birlikte hava taşımacilığı sektörünün hızlı bir şekilde büyüdügü ve sektörde faaliyet gösteren işletme sayısının arttığı görülmüştür. $\mathrm{Bu}$ durum hava taşımacıllğı sektörünü rekabetin daha yoğun bir şekilde yaşandığı bir sektör haline getirmiştir. Rekabetin yoğun bir şekilde yaşandığ 1 bu sektörde işletmeler mevcut faaliyetlerini devam ettirmek, faaliyet göstermiş oldukları pazarlarda paylarını arttırmak, gelir ve gider dengesini sağlamak amacıyla çeşitli stratejiler geliştirmek zorunda kalmışlardır. Bu stratejilerin bir kısmının maliyetleri düşürmeye, bir kısmının belirli pazarlarda faaliyet göstermeye, diğer bir kısmının ise rakip işletmelerden farklı stratejiler geliştirmeye yönelik olduğu görülmüştür. Bu stratejilerin devamında havayolu işletmeleri rakiplerine karşı rekabet avantajı kazanabilmek adına farklı iş modelleri geliştirmiştir.

Kârllı̆ı̆ın düşük ve maliyetlerin yüksek olduğu, talepte ani dalgalanmaların yaşandığı, rekabetin daha sık1 bir şekilde gerçekleştiği, teknolojik değişim ve dönüşümün daha fazla görüldüğü, operasyonel ve finansal faaliyetlerin birbirini daha çok etkilediği hava taşımacıllğı sektöründe faaliyet gösteren işletmeler faaliyetlerini sürdürmek, pazar paylarını arttırmak ve mevcut durumlarını rakip firmalarla karşılaştırmak için operasyonel ve finansal performanslarını sürekli gözden geçirmeleri gerekmektedir.

$\mathrm{Bu}$ çalışmanın amacı, farklı iş modelini uygulayan toplam 36 havayolu işletmesinin 2013-2018 dönemine ait operasyonel ve finansal açıdan etkinlik ölçümünün iki aşamalı veri zarflama analizi tekniği ile gerçekleştirilmesidir. Bu açıdan çalışmanın ilerleyen bölümlerinde literatürde yer alan benzer çalışmalara değinilmiş ve etkinlik ölçümü aşamasında kullanılan veri zarflama analizi tekniği hakkında bilgi verilmiştir. Sonraki bölümlerde ise kullanılan verilerden ve uygulanmış olan analizlerden ayrıntılı bir biçimde bahsedilmiştir. Son kısımda ise sonuç ve öneriler sunulmuştur.

\section{Literatür}

Hava taşımacillğı sektöründe operasyonel ve finansal göstergeler kullanılarak etkinlik ölçümü ile ilgili yapılmış çalışmalara bakıldığında veri zarflama analizi tekniğinin yaygın bir biçimde kullanıldığı görülmektedir. 1993 yılında hava taşımacıllğı sektöründe operasyonel açıdan etkinliğin veri zarflama analizi ile ölçüldüğ̈̈ ilk çalısmada Schefczyk (1993), farklı bölgelerde faaliyet gösteren 15 havayolu işletmesinin 1989-1992 dönemine ait etkinlik ölçümünü CCR modelini kullanarak gerçekleştirmiştir. Takip eden yıllarda Good vd. (1995), Avrupa ve Amerika merkezli faaliyet gösteren toplam 16 havayolu işletmesinin 19761986 dönemine ait etkinlik ölçümünü VZA aracilığ ile gerçekleştirmiştir. Sonraki ylllarda Alam ve Sickles (1998), Amerika merkezli faaliyet gösteren 11 havayolu işletmesinin operasyonel ve finansal açıdan etkinlik ölçümünü hem veri zarflama analizi hem de serbest atılabilir zarf analizi aracilığı ile gerçekleştirmişlerdir.

2000'li yıllara gelindiğinde etkinlik ölçümü ile ilgili yapılan çalışmalarda veri zarflama analizinin yanı sıra etkinlik değerlerine etki eden değişkenlerin tespit edilmesi amacıyla regresyon modellerinin kullanıldığı görülmüştür. Fethi vd. (2000), yapmış oldukları çalışmada Avrupa merkezli faaliyet gösteren 17 havayolu işletmesinin 1991-1995 dönemine ait etkinlik ölçümünü ilk aşamada veri zarflama analizi ile ölçmüş ikinci aşamada ise etkinlik değerlerine etki eden değişkenlerin tespit edilmesi amacıyla tobit regresyon modelini kullanmışlardır. Yapılan benzer bir çalışmada ise Scherega (2004), dünyanın çeşitli yerlerinde faaliyet gösteren 38 havayolu işletmesinin 1995-2000 dönemine ait etkinlik ölçümünü VZA ile ölçmüş ve etkinlik skorlarına etki eden değişkenleri tobit regresyon modeli aracilığ ile tahmin etmiştir. Daha sonraki yıllarda Chiou ve Chen (2006), Tayvan merkezli faaliyet gösteren bir havayolu işletmesinin 15 uçuş hattındaki etkinliğini veri zarflama analizinin CCR ve BCC modeli aracilığ ile ölçmüşlerdir.

Veri zarflama analizi ile ilgili yapılan bazı çalısmalarda ise karar verme birimlerinin sıralanmasına imkân sağlayan süper etkinlik modelinin kullanıldığ1 görülmüştür. Greer (2006) Amerika merkezli faaliyet 
gösteren 14 havayolu işletmesinin etkinliğini VZA ile ölçmüş ve süper etkinlik modeli aracilığ ile etkin olan havayolu işletmelerini kendi içerisinde sıralamıştır. Greer (2008) yapmış olduğu başka bir çalışmada ise bu kez Amerika'da faaliyet gösteren 12 havayolu işletmesinin 2000-2004 dönemine ait etkinlik ölçümünü veri zarflama analizi aracıllğı ile gerçekleştirmiş ve etkinlik değerlerindeki değişimin yönünü tespit etmek amacıyla malmquist toplam faktör verimliliği endeksini kullanmıştır. Barbot vd., (2008), yapmış oldukları çalışmada dünyanın farklı yerlerinde faaliyet gösteren 39 geleneksel ve 10 düşük maliyetli iş modelini uygulayan havayolu işletmelerinin etkinlik ölçümünü veri zarflama analizinin BCC modeli ile ölçmüş ve etkinlikteki değişimin yönünü toplam faktör verimlilik endeksi ile hesaplamışlardır. Aynı şekilde Bhadra (2009), Amerika'da faaliyet gösteren 8 geleneksel havayolu işletmesi ile 6 düşük maliyetli havayolu işletmesinin 1985-2006 dönemine ait etkinlik ölçümünü ilk aşamada veri zarflama analizi ile ölçmüştür. İkinci aşamada ise etkinlik skorlarına etki eden değişkenleri tobit regresyon modeli aracllğı ile tahmin etmiştir. İlerleyen dönemlerde ise etkinlik ölçümünün ikinci aşamasında kullanılan regresyon modellerinin çeşitlendiği görülmektedir. Wang vd. (2011), Amerika merkezli 30 havayolu işletmesinin etkinlik ölçümünü ilk aşamada veri zarflama analizi tekniği ile ölçmüştür. İkinci aşamada ise etkinlik değerlerine etki eden değişkenleri truncated regresyon modeli aracllğı ile tahmin etmiştir. Lee ve Worthinton (2014), yapmış oldukları benzer bir çalışmada 29 geleneksel ve 13 düşük maliyetli havayolu işletmesinin etkinlik ölçümünü ilk aşamada veri zarflama analizi aracıllğı ile gerçekleştirmişlerdir. Etkinlik skorları üzerinde etkili olan değişkenleri tespit etmek amacıyla truncated regresyon modelini kullanmışlardır.

Veri zarflama analizi tekniği kullanılarak yapılmış bazı çalışmalarda ise etkinlik ölçümünün farklı açılardan hesaplanmasına olanak sağlayan iki aşamalı veri zarflama analizi tekniğinin kullanıldığ1 görülmektedir. Zhu (2011), Amerika merkezli faaliyet gösteren 21 havayolu işletmesinin 2007-2008 dönemine ait etkinlik ölçümünü iki aşamalı veri zarflama analizi tekniği ile ölçmüştür. Yapılan benzer bir çalışmada Gramani (2012), operasyonel değişkenlerin toplam gelir üzerindeki etkisini tespit etmek amaciyla Brezilya'da faaliyet gösteren 16 ve Amerika'da faaliyet gösteren 18 havayolu işletmesinin etkinlik ölçümünü iki aşamalı veri zarflama analizi aracilı̆̆ ile gerçekleştirmiştir. Bir diğer çalışmada ise Lu vd., (2012), operasyonel değişkenlerin pazar etkinliği üzerindeki etkisini ölçmek amacıyla dünyanın birçok yerinde faaliyet gösteren 30 havayolu işletmesinin 2010 yllına ait etkinlik ölçümünü iki aşamalı veri zarflama analizi tekniği ile ölçmüştür.

Son yıllarda veri zarflama analizi ile ilgili yapılan bazı çalışmalarda ise aylak tabanlı modelin (Chang, Park, Jeong ve Lee, 2014), bazı çalışmalarda ise Dinamik (Omrani ve Soltanzadeh, 2016; Yu, Chen ve Chiang, 2017; Yu, Zhang, Zhang, Wang ve Cui, 2019) ve İlişkisel VZA (Lin ve Hong, 2019); gibi yeni VZA tekniklerinin kullanıldığı görülmektedir.

Bu çalışmada farklı iş modelini uygulayan havayolu işletmelerinin operasyonel ve finansal açıdan etkinlik ölçümü gerçekleştirilerek etkinlik skorları arasında anlamlı bir farklılığın olup olmadığı tespit edilmeye çalışılmaktadır. Alan yazında havayolu işletmelerinin uygulamış oldukları iş modeline göre sınıflandırılarak etkinlik ölçümünün hem operasyonel hem de finansal açıdan iki aşamalı veri zarflama analizi aracıllğ̆ ile gerçekleştirilmiş olduğu çalışma sayısının oldukça az olduğu tespit edilmiştir. Bu açıdan bu çalışmanın bu yönüyle literatüre katkı sağlayacağı düşünülmektedir.

\section{Veri Zarflama Analizi}

Veri zarflama analizi, birçok girdi ve çıktı kümesine sahip karar verme birimlerinin göreceli olarak etkinliğini ölçebilen ve doğrusal programlama temelini baz alarak karar verme birimlerini kendi içerisinde karşılaştırma olanağı sunan bir ölçüm yöntemidir (Lang, Yolalan ve Kettani, 1995, s. 473). VZA yöntemi benzer özelliklere sahip olan karar verme birimlerinin etkinliklerinin ölçülüp karşılaştırılması amacıyla geliştirilmiş olan bir yöntemdir (Yolalan , 1993, s. 27).

Veri zarflama analizi, birçok farklı ölçekteki girdi ve çıtı kümesine sahip olan karar verme birimlerinin etkinlik ölçümünün zor olduğu durumlarda kullanılabilen ve parametrik özelliklere sahip olmayan bir yöntemdir (Ramanathan, 2003, s. 61). Bunun yan1 sira veri zarflama analizi regresyon analizinin doğrudan uygulanmasının zor olduğu çok sayıda girdi ve çıktı değişkenine sahip karar verme birimlerinin üretim süreçlerinde birçok farklı açıdan etkinlik analizinin gerçekleştirilmesi amacıyla kullanılan bir yöntemdir (Akan ve Çalmaşur, 2011, s. 17). 
Veri zarflama analizinde etkinlik ölçümü gerçekleştirilecek olan karar verme birimlerinin aynı amaç ve hedeflere sahip olması, benzer özellik göstermesi ve yoğunluk ile büyüklük dışındaki özelliklerinin aynı olması beklenmektedir (Karsak ve İşcan, 2000, s. 3).

VZA, homojen yapıya sahip karar verme birimlerinin etkinlik ölçümünü girdi ve çıktı kümesi aracıllğ̣ ile ölçebilen bir analiz tekniğidir. Bununla birlikte VZA yöntemi etkinlik ölçümü aşamasında hiçbir üretim fonksiyonuna ihtiyaç duymadan etkinlik analizini gerçekleştirebilmektedir (Pourjavad ve Shirouyehzad, 2014, s. 144).

Veri zarflama analizinde en az girdi değişkenini kullanarak en çok çıktı değişkeni üreten karar verme birimleri belirlenmekte ve belirlenmiş olan bu karar verme birimleri aracıllğ ile etkinlik sınırı oluşturulmaktadır. Tespit edilmiş olan bu etkinlik sınırı referans noktası olarak tanımlanmakta ve etkin olmayan karar verme birimlerinin bu referans noktasına olan uzaklığ1 radyal olarak hesaplanmaktadır (Cook, Kress, ve Seiford, 1996, s. 2).

Veri zarflama analizi, ilk olarak 1978 yılında CCR modelinin kullanılmaya başlanması ile birlikte hem metedolojik hem de teorik açıdan hızlı bir gelişim süreci içerisine girmiştir. Takip eden yıllarda CCR modeline $\sum_{j=1}^{n} \beta_{j}=1$ şeklinde ifade edilen (Cooper, Seiford ve Zhu, 2011, s. 13) konvekslik kisitının eklenmesi ile ölçek etkinliği ile teknik etkinliğin ayrı ayrı hesaplanabilmesine olanak sağlayan BCC modeli geliştirilmiştir (Başkaya ve Avc1 Öztürk, 2012, s. 177).

\section{CCR Modeli}

Veri zarflama analizinde kullanılan ilk temel model olma özelliği taşıyan CCR modeli, 1978 yılında Charnes, Cooper ve Rhodes tarafindan geliştirilmiştir (Weng, Wu, Blackhurst ve Mackulak, 2009, s. 41). Karar verme birimlerinin toplam etkinlik değerlerini hesaplayıp etkinsizliğin miktarını ve kaynağını tespit edebilen CCR modeli ölçeğe göre sabit getiri varsayımını baz almaktadır (Charnes , Cooper ve Rhodes, 1978, s. 430).

CCR modelinde toplam etkinlik ölçümünün gerçekleşmesinden dolayı CCR modelinde etkin olan karar verme birimlerinin hem ölçek etkinliği hem de teknik etkinlik açısından etkin olması beklenmektedir (Lorcu, 2008, s. 71). CCR modelinin matematiksel gösterimi aşağıda yer almaktadır (Cooper, Seiford ve Zhu, 2011, s. 13):

$Q_{k}=\max \left(\theta+\varepsilon \sum_{i=1}^{m} S_{i}^{-}+\varepsilon \sum_{r=1}^{s} S_{r}^{+}\right)$

Kisitlar,

$\sum_{J=1}^{n} X_{i j} \beta_{j}+S_{i}^{-}-X_{i k}=0 \quad i=1, \ldots \ldots m$

$\sum_{J=1}^{n} Y_{r j} \beta_{j}-S_{i}^{-}-\beta_{j} Y_{k}=0 \quad r=1, \ldots p \quad j=1, \ldots n=1, \ldots . m$

$\beta_{j} \geq 0 \quad S_{i}^{-} \geq 0 \quad S_{r}^{+} \geq 0$

\section{BCC Modeli}

Banker, Charnes ve Cooper tarafindan ilk defa 1984 yılında kullanılmaya başlanan BCC modeli ölçeğe göre değişken getiri varsayımını baz almaktadır. CCR modeline konkvekslik kısıtının eklenmesi ile elde edilmiş olan BCC modelinde karar verme birimlerinin teknik ve ölçek etkinliği hesaplanabilmektedir (Elsayed ve Khalil, 2017, s. 2). BCC modelinin matematiksel gösterimi aşağıda yer almaktadır (Chen ve Ali, 2002, s. 477):

$E_{o}=\operatorname{Max}\left(\theta+\varepsilon \sum_{i=i}^{m} S_{i}^{-}+\varepsilon \sum_{r=1}^{p} S_{r}^{+}\right)$

Kisitlar, 


$$
\begin{array}{ll}
\sum_{j=1}^{n} X_{i j} \beta_{j}+S_{i}^{-}-X_{i k}=0 & i=1,2, \ldots m \\
\sum_{j=1}^{n} y_{r j} \beta_{j}-\theta Y_{r k}-S_{r}^{+}=0 & r=1,2, \ldots p \\
\sum_{j=1}^{n} \beta_{j}=1 & \\
\beta_{j} \geq 0 \quad S_{i}^{-} \geq 0 \quad S_{i}^{+} \geq 0 \quad j=1,2, \ldots n & i=1,2 \ldots . m \quad r=1,2, \ldots . p
\end{array}
$$

\section{Veri Zarflama Analizi Uygulamas1}

Bu çalışmada, dünyanın birçok noktasına uçuş faaliyeti gerçekleştiren ve farklı iş modelini uygulayan toplam 36 havayolu işletmesinin operasyonel ve finansal açıdan etkinlik ölçümü iki aşamalı veri zarflama analizi aracıllğı ile gerçekleştirilmiştir. Bu açıdan ilk aşamada havayolu işletmelerinin operasyonel açıdan ikinci aşamada ise operasyonel etkinliğin finansal etkinlik üzerindeki etkisinin tespit edilmesi amaciyla finansal açıdan etkinliği ölçülmüştür. Araştırma kapsamında havayolu işletmelerine ait operasyonel veriler havayolu işletmelerinin faaliyet raporlarından ve aylık olarak yayınlanan Airline Business dergisinden temin edilmiştir. Airline Business dergisinin söz konusu verileri havayolu işletmelerinden aldığ1 tespit edilmiştir. Havayolu işletmelerine ait finansal veriler ise Thomson Reuters Data Stream veri tabanından temin edilmiştir. Çalışmaya düşük maliyetli iş modelini uygulayan 17 havayolu işletmesi ile geleneksel iş modelini uygulayan 19 havayolu işletmesi dâhil edilmiştir.

Veri zarflama analizi tekniğinde girdi ve çıktı seçimi süreci analizin güvenilirliğini önemli derecede etkilemektedir. $\mathrm{Bu}$ açıdan gerek operasyonel açıdan gerekse finansal açıdan seçilen girdi ve çıktı değişkenleri alan yazında en çok kullanılan ve operasyonel performans ile finansal performansı en iyi

\begin{tabular}{|c|c|}
\hline Girdi Değişkenleri & Aç1klama \\
\hline Arz Edilen Koltuk Kilometre (ASK) & $\begin{array}{l}\text { Havayolu işletmelerinin satışa sunmuş oldukları koltuk sayısının uçuş } \\
\text { mesafesi ile çarpılması sonucunda bulunan değer }\end{array}$ \\
\hline Çalışan Sayısı & Havayolu işletmelerinde çalışan personel sayısı \\
\hline Uçak Sayısı & Havayolu işletmelerinin filolarında yer alan toplam uçak sayısı \\
\hline Çıktı Değişkenleri & Açıklama \\
\hline Yolcu Say1s1 & Havayolu işletmelerinin bir yıl boyunca taşıdığı toplam yolcu sayısı \\
\hline Ücretli Yolcu Kilometre (RPK) & $\begin{array}{l}\text { Havayolu işletmelerinin ücret karşılığında taşımış olduğu toplam yolcu } \\
\text { sayısının uçuş mesafesi ile çarpılması sonucunda bulunan değer }\end{array}$ \\
\hline Doluluk Oranı & $(\mathrm{RPK} / \mathrm{ASK}) \times 100$ \\
\hline
\end{tabular}
derecede yansıtan değişkenler arasından seçilmiştir. Çalışmada yer alan ve operasyonel performansı yansıtan girdi ve çıktı değişkenleri tablo 1'de yer almaktadır.

Tablo 1. Operasyonel Etkinlik Ölçümünde Kullanılan Girdi ve Çıktı Değisskenleri (1. Assama)

Analizin ikinci aşamasında operasyonel etkinliğin finansal etkinlik üzerindeki etkisinin tespit edilmesi

\begin{tabular}{|c|c|}
\hline Girdi Değişkenleri & Açıklama \\
\hline İlk Aşamada elde edilen etkinlik skorları & $\begin{array}{l}\text { Operasyonel etkinlik ölçümü sonucunda elde edilen etkinlik } \\
\text { skorları }\end{array}$ \\
\hline Ç1ktı Değişkenleri & Açıklama \\
\hline Net Kâr/ Net Satışlar & $\begin{array}{l}\text { Havayolu İşletmelerinin gerçekleştirmiş oldukları satışlardan ne } \\
\text { kadar kâr elde ettiklerini gösteren bir orandır. }\end{array}$ \\
\hline Net Kâr/ Toplam Varlıklar & $\begin{array}{l}\text { Havayolu İşletmelerinin varlıklarının kaç katı kadar satış } \\
\text { yaptığını gösteren bir orandır. }\end{array}$ \\
\hline
\end{tabular}
amacıyla operasyonel etkinlik ölçümü sonucunda elde edilen etkinlik skorları girdi değişkeni olarak analize dâhil edilmiştir. Finansal etkinlik ölçümünde kullanılan girdi ve çıktı değişkenleri tablo 2'de yer almaktadır.

Tablo 2. Finansal Etkinlik Ölçümünde Kullamlan Girdi ve Çıtı Değișkenleri (2. Așama) 
Geleneksel ve düşük maliyetli iş modelini uygulayan havayolu işletmelerinin 2013-2018 dönemine ait etkinlik ölçümü iki aşamalı veri zarflama analizi tekniği aracıllğı ile gerçekleştirilmiştir. Etkinlik ölçümü aşamasında Deap 2.1 yazılım programından yararlanılmışır. Analizin ilk aşamasında operasyonel açıdan ikinci aşamada ise finansal açıdan etkinlik ölçümü gerçekleştirilmiştir. Çalışmada kullanılan operasyonel ve finansal değişkenlerden dolayı çıktı odaklı veri zarflama analizi modelinin kullanılmasına karar verilmiştir.

$\mathrm{Bu}$ araştırmada veri zarflama analizinin temel modeli olarak kabul edilen CCR ve BCC modelleri kullanılmıştır. BCC modeli ile havayolu işletmelerinin teknik etkinliği ölçülebilirken CCR modeli ile havayolu işletmelerinin toplam etkinliği ölçülebilmektedir. Etkinlik değeri 1 olan havayolu işletmeleri etkin kabul edilirken etkinlik değeri 1'in altında olan havayolu işletmeleri etkin kabul edilmemektedir.

\section{Operasyonel Açıdan Etkinlik Analizi}

Geleneksel ve düşük maliyetli iş modelini uygulayan havayolu işletmelerinin operasyonel açıdan veri zarflama analizi sonucu elde edilen etkinlik skorları Tablo 3-4'te verilmiştir.

Tablo 3. Geleneksel Havayolu Işletmeleri (Operasyonel Etkinlik))

\begin{tabular}{|c|c|c|c|c|c|c|c|c|c|c|c|c|}
\hline \multirow[b]{2}{*}{ AIRLINES } & \multicolumn{2}{|c|}{2013} & \multicolumn{2}{|c|}{2014} & \multicolumn{2}{|c|}{2015} & \multicolumn{2}{|c|}{2016} & \multicolumn{2}{|c|}{2017} & \multicolumn{2}{|c|}{2018} \\
\hline & CCR & BCC & CCR & BCC & CCR & BCC & CCR & BCC & CCR & BCC & CCR & BCC \\
\hline AEROFLOT & 1.000 & 1.000 & 0.961 & 0.971 & 0.955 & 0.971 & 1.000 & 1.000 & 1.000 & 1.000 & 0.975 & 0.979 \\
\hline AIR CANADA & 1.000 & 1.000 & 1.000 & 1.000 & 1.000 & 1.000 & 1.000 & 1.000 & 1.000 & 1.000 & 1.000 & 1.000 \\
\hline AIR CHINA & 1.000 & 1.000 & 0.976 & 0.982 & 1.000 & 1.000 & 1.000 & 1.000 & 1.000 & 1.000 & 1.000 & 1.000 \\
\hline $\begin{array}{l}\text { AIR FRANCE - } \\
\text { KLM } \\
\text { AMERİCAN }\end{array}$ & 0.997 & 1.000 & 0.985 & 1.000 & 1.000 & 1.000 & 1.000 & 1.000 & 1.000 & 1.000 & 1.000 & 1.000 \\
\hline $\begin{array}{l}\text { AİRLINES } \\
\text { ALL NIPPON }\end{array}$ & 0.992 & 0.993 & 0.971 & 0.971 & 0.977 & 1.000 & 0.968 & 1.000 & 0.958 & 1.000 & 0.967 & 1.000 \\
\hline AİRWAYS & 0.921 & 0.939 & 0.976 & 1.000 & 1.000 & 1.000 & 1.000 & 1.000 & 0.978 & 0.994 & 1.000 & 1.000 \\
\hline AVIANCA & 1.000 & 1.000 & 1.000 & 1.000 & 1.000 & 1.000 & 1.000 & 1.000 & 1.000 & 1.000 & 1.000 & 1.000 \\
\hline $\begin{array}{l}\text { CHINA EASTERN } \\
\text { CHINA }\end{array}$ & 1.000 & 1.000 & 0.981 & 1.000 & 1.000 & 1.000 & 0.974 & 1.000 & 0.961 & 1.000 & 0.974 & 1.000 \\
\hline SOUTHERN & 0.962 & 0.965 & 0.952 & 0.964 & 0.959 & 0.965 & 0.967 & 0.978 & 0.969 & 0.976 & 0.965 & 0.977 \\
\hline DELTA AIR LINES & 1.000 & 1.000 & 1.000 & 1.000 & 1.000 & 1.000 & 1.000 & 1.000 & 1.000 & 1.000 & 1.000 & 1.000 \\
\hline $\begin{array}{l}\text { JAPAN AİRLINES } \\
\text { KOREAN AIR }\end{array}$ & 0.886 & 0.887 & 0.872 & 0.872 & 0.916 & 0.916 & 0.923 & 0.924 & 1.000 & 1.000 & 0.983 & 0.988 \\
\hline LINES & 1.000 & 1.000 & 0.987 & 1.000 & 1.000 & 1.000 & 0.971 & 0.988 & 0.983 & 0.985 & 1.000 & 1.000 \\
\hline LATAM AIRLINES & 1.000 & 1.000 & 1.000 & 1.000 & 1.000 & 1.000 & 1.000 & 1.000 & 1.000 & 1.000 & 0.971 & 0.983 \\
\hline $\begin{array}{l}\text { LUFTHANSA } \\
\text { QANTAS }\end{array}$ & 0.957 & 1.000 & 0.959 & 1.000 & 0.981 & 1.000 & 0.939 & 0.942 & 0.948 & 0.961 & 0.941 & 0.949 \\
\hline $\begin{array}{l}\text { AIRWAYS } \\
\text { SCANDINAVIAN }\end{array}$ & 1.000 & 1.000 & 1.000 & 1.000 & 1.000 & 1.000 & 1.000 & 1.000 & 1.000 & 1.000 & 0.971 & 0.982 \\
\hline AIRLINES & 1.000 & 1.000 & 1.000 & 1.000 & 1.000 & 1.000 & 1.000 & 1.000 & 1.000 & 1.000 & 1.000 & 1.000 \\
\hline SKYWEST & 1.000 & 1.000 & 1.000 & 1.000 & 1.000 & 1.000 & 1.000 & 1.000 & 1.000 & 1.000 & 1.000 & 1.000 \\
\hline $\begin{array}{l}\text { TURK HAVA } \\
\text { YOLLARI } \\
\text { UNITED }\end{array}$ & 1.000 & 1.000 & 1.000 & 1.000 & 1.000 & 1.000 & 0.989 & 1.000 & 1.000 & 1.000 & 1.000 & 1.000 \\
\hline CONTINENTAL & 1.000 & 1.000 & 0.988 & 0.991 & 1.000 & 1.000 & 0.991 & 1.000 & 0.972 & 1.000 & 0.983 & 1.000 \\
\hline
\end{tabular}

Tablo 3'e göre VZA analizi aracilğı ile gerçekleştirilen etkinlik ölçümü sonucunda geleneksel havayolu işletmeleri içerisinde Air Canada, Avianca, Delta Airlines, Scandinavian Airlines ve Skywest işletmelerinin operasyonel açıdan tüm dönem boyunca etkin oldukları China Southern işletmesinin ise tüm dönem boyunca etkin olmadığ görülmüştür. Air China işletmesinin sadece 2014 yılında, Latam Airlines ile Qantas Airways işletmelerinin sadece 2018 yllında etkin olmadıkları tespit edilmiştir. Japan Airlines işletmesinin ise sadece 2017 yllında etkin olduğu görülmüştür.

Air France- KLM işletmesinin 2013 ve 2014 yllında American Airlines işletmesinin 2015-2018 döneminde, All Nippon ile Korean Airlines işletmelerinin 2014 yllinda, China Eastern işletmesinin 2014, 2016, 2017 ve 2018 yllarında, Lufthansa işletmesinin 2013-2015 döneminde, Türk havayolları işletmesinin 2016 yllında ve United Continental işletmesinin 2016-2018 döneminde BCC modeline göre etkin durumdayken CCR modeline göre etkin olmadığı tespit edilmiştir. 
Tablo 4. Düşük Maliyetli Havayolu Issletmeleri (Operasyonel Etkinlike)

\begin{tabular}{|c|c|c|c|c|c|c|c|c|c|c|c|c|}
\hline \multirow[b]{2}{*}{ AIRLINES } & \multicolumn{2}{|c|}{2013} & \multicolumn{2}{|c|}{2014} & \multicolumn{2}{|c|}{2015} & \multicolumn{2}{|c|}{2016} & \multicolumn{2}{|c|}{2017} & \multicolumn{2}{|c|}{2018} \\
\hline & CCR & BCC & CCR & BCC & CCR & BCC & CCR & BCC & CCR & BCC & CCR & BCC \\
\hline AIR ARABIA & 1.000 & 1.000 & 1.000 & 1.000 & 1.000 & 1.000 & 1.000 & 1.000 & 1.000 & 1.000 & 1.000 & 1.000 \\
\hline AIRASIA & 0.937 & 0.941 & 0.911 & 0.911 & 1.000 & 1.000 & 1.000 & 1.000 & 1.000 & 1.000 & 1.000 & 1.000 \\
\hline $\begin{array}{l}\text { ALLEGİANT } \\
\text { AIR }\end{array}$ & 1.000 & 1.000 & 1.000 & 1.000 & 0.624 & 0.963 & 1.000 & 1.000 & 1.000 & 1.000 & 1.000 & 1.000 \\
\hline $\begin{array}{l}\text { CEBU PASİFIC } \\
\text { AİR }\end{array}$ & 1.000 & 1.000 & 1.000 & 1.000 & 1.000 & 1.000 & 1.000 & 1.000 & 1.000 & 1.000 & 1.000 & 1.000 \\
\hline EASYJET & 1.000 & 1.000 & 1.000 & 1.000 & 0.909 & 1.000 & 1.000 & 1.000 & 1.000 & 1.000 & 1.000 & 1.000 \\
\hline GOL LINHAS & 0.831 & 0.863 & 0.914 & 0.941 & 0.895 & 0.913 & 0.879 & 0.886 & 0.904 & 0.917 & 0.891 & 0.916 \\
\hline İNDİGO & 0.868 & 0.868 & 0.839 & 0.842 & 0.914 & 0.932 & 0.958 & 0.972 & 1.000 & 1.000 & 1.000 & 1.000 \\
\hline $\begin{array}{l}\text { JETBLUE } \\
\text { AIRWAYS }\end{array}$ & 0.893 & 0.921 & 0.903 & 0.916 & 0.732 & 0.914 & 0.908 & 0.915 & 0.893 & 0.899 & 0.901 & 0.909 \\
\hline LION AİR & 1.000 & 1.000 & 1.000 & 1.000 & 1.000 & 1.000 & 1.000 & 1.000 & 1.000 & 1.000 & 1.000 & 1.000 \\
\hline $\begin{array}{l}\text { NORWEGIAN } \\
\text { AIR }\end{array}$ & 0.866 & 0.874 & 1.000 & 1.000 & 0.874 & 0.958 & 0.951 & 0.963 & 0.951 & 1.000 & 1.000 & 1.000 \\
\hline RYANAIR & 0.948 & 1.000 & 0.997 & 1.000 & 0.991 & 1.000 & 1.000 & 1.000 & 1.000 & 1.000 & 1.000 & 1.000 \\
\hline $\begin{array}{l}\text { SOUTHWEST } \\
\text { AIRLINES }\end{array}$ & 0.868 & 1.000 & 0.894 & 1.000 & 0.746 & 1.000 & 0.893 & 1.000 & 0.878 & 1.000 & 0.872 & 1.000 \\
\hline $\begin{array}{l}\text { SPIRİT } \\
\text { AİRLINES }\end{array}$ & 0.947 & 0.961 & 0.934 & 0.937 & 0.847 & 0.934 & 0.925 & 0.932 & 0.903 & 0.905 & 0.912 & 0.914 \\
\hline $\begin{array}{l}\text { SPRİNG } \\
\text { AİRLINES }\end{array}$ & 1.000 & 1.000 & 1.000 & 1.000 & 0.986 & 1.000 & 1.000 & 1.000 & 1.000 & 1.000 & 1.000 & 1.000 \\
\hline $\begin{array}{l}\text { VUELING } \\
\text { AIRLINES }\end{array}$ & 0.988 & 1.000 & 0.898 & 0.911 & 0.819 & 0.912 & 0.971 & 0.983 & 1.000 & 1.000 & 1.000 & 1.000 \\
\hline $\begin{array}{l}\text { WESTJET } \\
\text { AIRLINES }\end{array}$ & 0.872 & 0.891 & 0.892 & 0.896 & 0.704 & 0.861 & 0.883 & 0.891 & 0.903 & 0.914 & 0.913 & 0.922 \\
\hline WIZZZ AIR & 1.000 & 1.000 & 1.000 & 1.000 & 1.000 & 1.000 & 1.000 & 1.000 & 1.000 & 1.000 & 1.000 & 1.000 \\
\hline
\end{tabular}

Tablo 4'e göre veri zarflama analizi aracıllı̆̆ ile gerçekleştirilen etkinlik ölçümü sonucunda operasyonel açıdan düşük maliyetli havayolu işletmeleri içerisinde Air Arabia, Cebu Pasific Air, Lion Air ve Wizz Air işletmelerinin tüm dönem boyunca etkin oldukları görülürken Gol Linhas, Jet Blue Airways, Spirit Airlines ve Westjet işletmelerinin tüm dönem boyunca etkin olmadıkları görülmüştür.

Easyjet işletmesinin 2015 yllında, Norwegian Air işletmesinin 2017 yılında, Ryanair işletmesinin 20132015 döneminde, Southwest işletmesinin tüm dönem boyunca, Spring Airlines işletmesinin 2015 yllında ve Vueling Airlines işletmesinin 2013 yılında BCC modeline göre etkin durumdayken CCR modeline göre etkin olmadığı tespit edilmiştir.

\section{Finansal Açıdan Etkinlik Analizi}

Geleneksel ve düşük maliyetli iş modelini uygulayan havayolu işletmelerinin finansal açıdan VZA analizi sonucu elde edilen etkinlik skorları Tablo 5 ve 6'da verilmiştir. 
Tablo 5. Geleneksel Havayolu İsletmeleri (Finansal Etkinlik)

\begin{tabular}{|c|c|c|c|c|c|c|c|c|c|c|c|c|}
\hline \multirow[b]{2}{*}{ AIRLINES } & \multicolumn{2}{|c|}{2013} & \multicolumn{2}{|c|}{2014} & \multicolumn{2}{|c|}{2015} & \multicolumn{2}{|c|}{2016} & \multicolumn{2}{|c|}{2017} & \multicolumn{2}{|c|}{2018} \\
\hline & CCR & BCC & CCR & BCC & CCR & BCC & CCR & BCC & CCR & BCC & CCR & BCC \\
\hline AEROFLOT & 0.182 & 0.182 & 0.041 & 0.045 & 0.055 & 0.059 & 1.000 & 1.000 & 0.583 & 0.583 & 0.252 & 0.265 \\
\hline AIR CANADA & 0.041 & 0.041 & 0.052 & 0.053 & 0.118 & 0.118 & 0.585 & 0.585 & 1.000 & 1.000 & 0.124 & 0.125 \\
\hline AIR CHINA & 0.107 & 0.107 & 0.213 & 0.221 & 0.251 & 0.252 & 0.545 & 0.545 & 0.462 & 0.462 & 0.494 & 0.502 \\
\hline $\begin{array}{l}\text { AIR FRANCE - } \\
\text { KLM }\end{array}$ & 0.036 & 0.037 & 0.048 & 0.048 & 0.047 & 0.047 & 0.293 & 0.293 & 0.075 & 0.075 & 0.124 & 0.125 \\
\hline $\begin{array}{l}\text { AMERICAN } \\
\text { AİRLINES }\end{array}$ & 0.041 & 0.042 & 0.376 & 0.396 & 1.000 & 1.000 & 0.657 & 0.688 & 0.401 & 0.613 & 0.305 & 0.354 \\
\hline $\begin{array}{l}\text { ALL NIPPON } \\
\text { AİRWAYS }\end{array}$ & 0.078 & 0.118 & 0.107 & 0.111 & 0.191 & 0.192 & 0.455 & 0.455 & 0.708 & 0.861 & 0.741 & 0.751 \\
\hline AVIANCA & 0.227 & 0.227 & 0.104 & 0.105 & 0.053 & 0.053 & 0.074 & 0.074 & 0.083 & 0.083 & 0.086 & 0.087 \\
\hline $\begin{array}{l}\text { CHINA } \\
\text { EASTERN }\end{array}$ & 0.107 & 0.107 & 0.212 & 0.216 & 0.208 & 0.208 & 0.373 & 0.387 & 0.48 & 0.706 & 0.202 & 0.219 \\
\hline $\begin{array}{l}\text { CHINA } \\
\text { SOUTHERN }\end{array}$ & 0.074 & 0.088 & 0.109 & 0.121 & 0.139 & 0.161 & 0.376 & 0.394 & 0.397 & 0.537 & 0.204 & 0.241 \\
\hline $\begin{array}{l}\text { DELTA AIR } \\
\text { LINES }\end{array}$ & 1.000 & 1.000 & 0.104 & 0.105 & 0.549 & 0.549 & 1.000 & 1.000 & 0.692 & 0.692 & 0.889 & 0.901 \\
\hline JAPAN AİRLINES & 0.616 & 1.000 & 0.658 & 1.000 & 0.771 & 1.000 & 0.912 & 1.000 & 1.000 & 1.000 & 1.000 & 1.000 \\
\hline $\begin{array}{l}\text { KOREAN AIR } \\
\text { LINES }\end{array}$ & 0.036 & 0.036 & 0.047 & 0.048 & 0.047 & 0.047 & 0.064 & 0.066 & 0.548 & 0.655 & 0.086 & 0.087 \\
\hline $\begin{array}{l}\text { LATAM } \\
\text { AIRLINES }\end{array}$ & 0.036 & 0.036 & 0.045 & 0.045 & 0.053 & 0.053 & 0.091 & 0.091 & 0.154 & 0.154 & 0.202 & 0.226 \\
\hline LUFTHANSA & 0.047 & 0.055 & 0.041 & 0.045 & 0.294 & 0.294 & 0.519 & 0.558 & 0.615 & 1.000 & 0.783 & 1.000 \\
\hline $\begin{array}{l}\text { QANTAS } \\
\text { AIRWAYS }\end{array}$ & 0.032 & 0.032 & 0.042 & 0.043 & 0.359 & 0.359 & 0.488 & 0.488 & 0.462 & 0.462 & 0.633 & 0.677 \\
\hline $\begin{array}{l}\text { SCANDINAVIAN } \\
\text { AIRLINES }\end{array}$ & 0.041 & 0.041 & 0.035 & 0.035 & 0.176 & 0.176 & 0.329 & 0.329 & 0.333 & 0.333 & 0.494 & 0.501 \\
\hline SKYWEST & 0.071 & 0.071 & 0.045 & 0.045 & 0.167 & 0.167 & 0.066 & 0.066 & 1.000 & 1.000 & 0.889 & 0.901 \\
\hline $\begin{array}{l}\text { TURK HAVA } \\
\text { YOLLARI }\end{array}$ & 0.286 & 0.286 & 0.469 & 0.474 & 1.000 & 1.000 & 0.065 & 0.068 & 0.154 & 0.154 & 0.593 & 0.602 \\
\hline $\begin{array}{l}\text { UNITED } \\
\text { CONTINENTAL }\end{array}$ & 0.136 & 0.136 & 1.000 & 1.000 & 0.047 & 0.047 & 0.591 & 0.596 & 0.475 & 0.614 & 0.625 & 0.625 \\
\hline
\end{tabular}

Tablo 5'e göre veri zarflama analizi aracıllğı ile finansal açıdan yapılan etkinlik ölçümü sonucunda geleneksel havayolu işletmeleri içerisinde Aeroflot işletmesinin 2016 yilında, Air Canada ile Skywest işletmesinin 2017 yılında, American Airlines işletmesinin 2015 yllında, Delta Airlines işletmesinin 2013 ve 2016 yıllarında, Türk Hava Yolları işletmesinin 2015 yılında ve United Continental işletmesinin ise 2014 yllında etkinlik sinırına ulaştığı görülmüştür.

Japan Airlines işletmesinin 2013-2016 döneminde ve Lufthansa işletmesinin ise 2017-2018 döneminde CCR modeli açısından etkin değilken BCC modeli açısından etkin olduğu görülmüștür. 
Tablo 6. Düşük Maliyetli Havayolu İsletmeleri (Finansal Etkinlik)

\begin{tabular}{|c|c|c|c|c|c|c|c|c|c|c|c|c|}
\hline \multirow[b]{2}{*}{ AIRLINES } & \multicolumn{2}{|c|}{2013} & \multicolumn{2}{|c|}{2014} & \multicolumn{2}{|c|}{2015} & \multicolumn{2}{|c|}{2016} & \multicolumn{2}{|c|}{2017} & \multicolumn{2}{|c|}{2018} \\
\hline & CCR & BCC & CCR & BCC & CCR & BCC & CCR & BCC & CCR & BCC & CCR & BCC \\
\hline AIR ARABIA & 1.000 & 1.000 & 1.000 & 1.000 & 0.501 & 0.501 & 0.464 & 0.464 & 0.773 & 0.773 & 0.024 & 0.024 \\
\hline AIRASIA & 0.575 & 0.659 & 0.076 & 0.102 & 0.308 & 0.308 & 1.000 & 1.000 & 0.818 & 0.818 & 0.050 & 0.050 \\
\hline $\begin{array}{l}\text { ALLEGİANT } \\
\text { AIR }\end{array}$ & 0.764 & 0.788 & 0.565 & 0.565 & 1.000 & 1.000 & 0.737 & 0.737 & 0.639 & 0.639 & 0.501 & 0.502 \\
\hline $\begin{array}{l}\text { CEBU PASİFIC } \\
\text { AİR }\end{array}$ & 0.084 & 0.086 & 0.133 & 0.133 & 0.352 & 0.356 & 0.645 & 0.645 & 0.582 & 0.582 & 0.251 & 0.252 \\
\hline EASYJET & 0.828 & 0.848 & 0.652 & 0.652 & 0.631 & 0.648 & 0.408 & 0.408 & 0.316 & 0.316 & 0.391 & 0.391 \\
\hline GOL LINHAS & 0.062 & 1.000 & 0.051 & 0.065 & 0.051 & 0.061 & 0.569 & 1.000 & 0.059 & 0.071 & 0.043 & 1.000 \\
\hline İNDİGO & 0.961 & 1.000 & 0.362 & 1.000 & 1.000 & 1.000 & 0.731 & 0.847 & 1.000 & 1.000 & 0.846 & 0.846 \\
\hline $\begin{array}{l}\text { JETBLUE } \\
\text { AIRWAYS }\end{array}$ & 0.269 & 0.335 & 0.528 & 0.746 & 0.582 & 0.773 & 0.536 & 0.814 & 0.907 & 1.000 & 0.171 & 1.000 \\
\hline LION AİR & 0.577 & 0.601 & 0.381 & 0.381 & 0.466 & 0.474 & 0.201 & 0.202 & 0.412 & 0.412 & 0.308 & 0.308 \\
\hline $\begin{array}{l}\text { NORWEGIAN } \\
\text { AIR }\end{array}$ & 0.192 & 0.263 & 0.049 & 0.049 & 0.061 & 0.062 & 0.188 & 0.228 & 0.056 & 0.057 & 0.062 & 0.062 \\
\hline RYANAIR & 0.917 & 0.997 & 1.000 & 1.000 & 1.000 & 1.000 & 0.782 & 0.782 & 1.000 & 1.000 & 1.000 & 1.000 \\
\hline $\begin{array}{l}\text { SOUTHWEST } \\
\text { AIRLINES }\end{array}$ & 0.382 & 0.502 & 0.485 & 0.695 & 0.605 & 0.624 & 0.592 & 0.994 & 0.981 & 1.000 & 0.811 & 1.000 \\
\hline $\begin{array}{l}\text { SPİRITT } \\
\text { AİRLINES }\end{array}$ & 1.000 & 1.000 & 0.961 & 1.000 & 0.846 & 0.945 & 0.526 & 0.724 & 0.841 & 0.978 & 0.274 & 0.468 \\
\hline $\begin{array}{l}\text { SPRINNG } \\
\text { AİRLINES }\end{array}$ & 0.912 & 0.934 & 0.812 & 0.812 & 0.637 & 0.638 & 0.424 & 0.424 & 0.545 & 0.545 & 0.551 & 0.553 \\
\hline $\begin{array}{l}\text { VUELING } \\
\text { AIRLINES }\end{array}$ & 0.641 & 0.667 & 0.435 & 0.651 & 0.823 & 0.982 & 0.154 & 0.171 & 0.471 & 0.471 & 0.615 & 0.615 \\
\hline $\begin{array}{l}\text { WESTJET } \\
\text { AIRLINES }\end{array}$ & 0.656 & 0.859 & 0.551 & 0.827 & 0.523 & 1.000 & 0.349 & 0.727 & 0.322 & 0.361 & 0.111 & 0.341 \\
\hline WIZZZ AIR & 0.384 & 0.401 & 1.000 & 1.000 & 0.984 & 1.000 & 1.000 & 1.000 & 1.000 & 1.000 & 1.000 & 1.000 \\
\hline
\end{tabular}

Tablo 6'ya göre veri zarflama analizi aracıllğı ile finansal açıdan yapılan etkinlik ölçümü sonucunda düşük maliyetli havayolu işletmeleri içerisinde Air Arabia işletmesinin 2013-2014 döneminde, Air Asia işletmesinin 2016 yllında, Allegiant işletmesinin 2015 yllında, Ryanair işletmesinin 2014-2015 ile 2017-2018 döneminde, Spirit Airlines işletmesinin 2013 ve Wizz Air işletmesinin 2014 yllı ile 2016-2018 döneminde etkin olduğu tespit edilmiştir.

Gol Linhas işletmesinin 2013, 2016 ve 2018 yllarında, Indigo işletmesinin 2013-2014 döneminde, Jet Blue Airways ile Southwest Airlines işletmesinin 2017-2018 döneminde, Spirit Airlines işletmesinin 2014 yllında ve Westjet ile Wizz Air işletmelerinin 2015 yllında CCR modeline göre etkin değilken BCC modeline göre etkin çıktıkları görülmüştür.

\section{Sonuç ve Öneriler}

Geleneksel ve düşük maliyetli iş modelini uygulayan havayolu işletmelerinin 2013-2018 dönemine ait operasyonel ve finansal performansının iki aşamalı veri zarflama analizi tekniği ile karşılaştırıldığ bu çalışmada ilk olarak havayolu işletmelerinin operasyonel açıdan daha sonraki aşamada ise finansal açıdan etkinlik ölçümü gerçekleştirilmiştir.

Veri zarflama analizinin çıtı odaklı CCR ve BCC modeli ile operasyonel açıdan yapılan etkinlik ölçümü sonucunda geleneksel havayolu işletmeleri içerisinde etkin olan işletme sayısının \% 68 , düşük maliyetli havayolu işletmeleri içerisinde ise etkin olan işletme sayısının \% 58 civarında olduğu tespit edilmiştir. Bu açıdan geleneksel iş modelini uygulayan havayolu işletmelerinin operasyonel etkinlik açısından düşük maliyetli iş modelini uygulayan havayolu işletmelerine nazaran daha iyi performans sergilediği söylenebilmektedir. Finansal etkinlik açısından bakıldığında ise geleneksel havayolu işletmeleri içerisinde etkin olan işletme sayısının \% 12, düşük maliyetli havayolu işletmeleri içerisinde ise etkin olan işletme sayısının \% 21 civarında olduğu tespit edilmiştir. Bu açıldan düşük maliyetli havayolu işletmelerinin finansal etkinlik açısından daha iyi bir durumda oldukları söylenebilmektedir. Genel olarak bakıldığında ise 
geleneksel ve düşük maliyetli havayolu işletmelerinin operasyonel açından elde etmiş oldukları başarıyı finansal başarıya dönüştüremediği görülmüştür.

2013-2018 dönemi itibariyle araştırmaya dâhil edilen geleneksel havayolu işletmeleri içerisinde operasyonel etkinlik açısından 5 havayolu işletmesinin (Air Canada, Avianca, Delta Airlines, Scandinavian Airlines, Skywest) tüm dönem boyunca etkin çıktığı 1 havayolu işletmesinin (China Southern) ise bütün dönem boyunca etkin çıkmadığı görülmüştür. Finansal etkinlik açıdan ise Japan Airlines dışındaki tüm işletmelerin neredeyse bütün dönem boyunca etkin olmadığı tespit edilmiştir. Air Canada, Avianca, Delta Airlines, Scandinavian Airlines ve Skywest işletmelerinin operasyonel açıdan elde etmiş oldukları başarıyı finansal başarıya dönüştüremedikleri söylenebilmektedir.

Araştırmaya dâhil edilen düşük maliyetli havayolu işletmeleri içerisinde operasyonel açıdan 4 havayolu işletmesinin (Air Arabia, Cebu Pasific Air, Lion Air, Wizz Air) bütün dönem boyunca etkin olduğu, 4 havayolu işletmesinin (Gol Linhas, Jet Blue Airways, Spirit Airlines, Westjet) ise tüm dönem boyunca etkin olmadığı görülmüştür. Finansal etkinlik açıdan ise Wizz Air, Ryanair, Indigo ve Air Arabia işletmelerinin diğer işletmelere nazaran daha iyi durumda oldukları görülmüştür. Cebu Pasific Air ve Lion Air işletmelerinin operasyonel açıdan elde etmiş olduklanı başarı1 finansal başarıya dönüştüremedikleri söylenebilmektedir.

Analize dâhil edilen geleneksel ve düşük maliyetli havayolu işletmeleri içerisinde operasyonel açıdan etkin çıkan 3 havayolu işletmesinin (Air Canada, Delta Airlines, Skywest) Kuzey Amerika merkezli, 3 havayolu işletmesinin (Air Arabia, Cebu Pasific Air, Lion Air) Asya merkezli, 2 havayolu işletmesinin (Scandinavian Airlines, Wizz Air) Avrupa merkezli ve 1 havayolu işletmesinin (Avianca) Güney Amerika merkezli olduğu tespit edilmiştir. Bu açıdan etkin olan işletmeler içerisinde uzun menzilli uçuş yapan işletme sayısının daha fazla olduğu görülmüştür. Analiz sonucunda elde edilen bulguların Saranga ve Nagpal (2016) ile Kiracı ve Asker’in (2019) çalışmalarının sonuçları ile uyumlu olduğu görülmüştür.

Veri zarflama analizi ile yapılan etkinlik ölçümünde girdi ve çıktı değişkenlerinin değişmesi etkinlik ölçümü sonuçlarını değiştirebilmektedir. Ayrıca hava taşımacılloğı sektöründe ülkeden ülkeye değişiklik gösteren yapisal düzenlemeler, sağlanan kamusal destekler ve vergilendirme şekli de etkinlik ölçümünü doğrudan etkiyebilmekte ve sonuçların değişmesine neden olabilmektedir.

Farklı iş modelini uygulayan havayolu işletmelerinin hem operasyonel hem de finansal etkinlik analizi değerlendirildiğinde, işletmeler açısından farklı sonuçların ortaya çıktığı tespit edilmiştir. Bu kapsamda elde edilen sonuçların, havayolu taşımacıllğı sektöründe faaliyet gösteren işletmelerin yöneticilerine bu sonuçları analiz edip değerlendirme imkânı sunarak operasyonel ve finansal etkinliğin arttırılmasına yönelik stratejilerin geliştirilmesine katkı sağlayacağı düşünülmektedir.

Bu çalışmada geleneksel ve düşük maliyetli iş modelini uygulayan havayolu işletmelerinin finansal ve operasyonel açıdan etkinliği incelenmiștir. Bu açıdan ilerleyen dönemlerde yapılacak olan çalışmalarda daha geniş bir örneklem üzerinden havayolu işletmelerinin çevresel ve sürdürülebilirlik açısından da etkinliği incelenebilir.

\section{Etik Beyan}

"Havayolu İsletmelerinde İki Aşamah Veri Zarflama Analizi İle Etkinlik Ölçümü” başlıklı çalışmanın yazım sürecinde bilimsel kurallara, etik ve alıntı kurallarına uyulmuş; toplanan veriler üzerinde herhangi bir tahrifat yapılmamış ve bu çalışma herhangi başka bir akademik yayın ortamına değerlendirme için gönderilmemiştir. $\mathrm{Bu}$ araştırmada hazır veri seti kullanıldığı için etik kurul kararı zorunluluğu taşımamaktadır.

\section{Kaynakça}

Akan, Y. ve Çalmaşur, G. (2011). Etkinliğin hesaplanmasında veri zarflama analizi ve stokastik sınır yaklaşımı yöntemlerinin karşılaştırılması. Atatürk Üniveristesi İktisadi İdari Bilimler Dergisi, 25(0), 13-32. Erişim adresi: https://dergipark.org.tr/tr/download/article-file/30431

Alam, I. S. ve Sickles, R. C. (1998). The relationship between stock market returns and technical efficiency innovations: Evidence from the US airline industry. Journal of Productivity Analysis, 9(1), 35-51. Erişim adresi: https://link.springer.com/content/pdf/10.1023/A:1018368313411.pdf.

Barbot, C., Costa, A. ve Sochirca, E. (2008). Airlines performance in the new market context: A comparative productivity. Journal of Air Transport Management, 14(5), 270-274. doi.org/10.1016/j.jairtraman.2008.05.003 
Başkaya, Z. ve Avcı Öztürk, B. (2012). Measuring financial efficiency of cement firms listed in istanbul stock exchance via fuzzy data enveleopment analysis. Mubasebe ve Finansman Dergisi, 54(2), 175-188. Erişim adresi: http://journal.mufad.org.tr/attachments/article/651/10.pdf

Bhadra, D. (2009). Race to the bottom or swimming upstream: Performance analysis of US airlines. Journal of Air Transport Management, 15(5), 227-235. doi.org/10.1016/j.jairtraman.2008.09.014

Chang, Y.-T., Park, H.-s., Jeong, J.-b. ve Lee, J.-w. (2014). Evaluating economic and environmental efficiency of global airlines: A SBM-DEA approach. Transportation Research Part D, 27(1), 46-50. doi.org/10.1016/j.trd.2013.12.013

Charnes, A., Cooper, W. W. ve Rhodes, E. L. (1978). Measuring the efficiency of decision making units. European Journal of Operational Research, 2(6), 429-444. doi.org/10.1016/0377-2217(78)90138-8

Chen, Y. ve Ali, A. I. (2002). Continuous optimization output-input ratio analysis and dea frontier. European Journal of Operational Research, 142(3), 476-479. doi.org/10.1016/S0377-2217(01)00318-6

Chiou, Y. C. ve Chen, Y. H. (2006). Route-based performance evaluation of Taiwanese domestic airlines using data envelopment analysis. Transportation Research Part E: Logistics and Transportation Review, 42(2), 116-127. doi.org/10.1016/j.tre.2007.01.004

Cook, W. D., Kress, M. ve Seiford, L. (1996). Data Envelopment Analysis in the Presence of both Quantitative and Qualitative Factors. Journal of the Operational Research Society, 47(7), 945-953. DOI: 10.2307/3010140

Cooper, W. W., Seiford, L. M. ve Zhu, J. (2011). Handbook on data envelopment analysis history, models and interpretations. International Series in Operations Research and Management Science, 164(1), 1-39. DOI: 10.1007/978-14419-6151-8

Elsayed, A. ve Khalil, N. S. (2017). Evaluate and analysis efficiency of safaga port using DEA-CCR, BCC and SBM models-comparison with DP world sokhna. IOP Conference Series: Materials Science and Engineering, 245(4), 1-11. doi:10.1088/1757-899X/245/4/042033

Fethi, M. D., Jackson, P. M. ve Weyman-Jones, T. G. (2000). Measuring the efficiency of European airlines: an application of $D E A$ and Tobit Analysis. Leicester: Efficiency and Productivity Research Unit, University of Leicester. http://www.le.ac.uk/ulsm/research/epru/dispaper.html

Good, D. H., Röller, L.-H. ve Sickles, R. C. (1995). Airline efficiency differences between Europe and the US: Implications for the pace of EC integration and domestic regulation. European Journal of Operational Research, 80(3), 508-518. doi.org/10.1016/0377-2217(94)00134-X

Gramani, M. C. (2012). Efficiency decomposition approach: A cross-country airline analysis. Expert Systems with Applications, 39(5), 5815-5819. doi.org/10.1016/j.eswa.2011.11.086

Greer, M. (2006). Are The Discount Airlines Actually More Efficient Than The Legacy Carriers? A Data Envelopment Analysis. International Journal of Transport Economics, 33(1), 37-55. Erişim adresi: https://www.jstor.org/stable/pdf/42747777.pdf

Greer, M. (2008). Nothing focuses the mind on productivity quite like the fear of liquidation: Changes in airline productivity in the United States, 2000-2004. Transportation Research Part A: Policy and Practice, 42(2), 414-426. doi.org/10.1016/j.tra.2007.11.001

Karsak, E. ve İşcan, F. (2000). Çimento sektöründe göreli faaliyet performanslarının ağırlık kısıtlamaları ve çapraz etkinlik kullanılarak veri zarflama analizi ile değerlendirilmesi. Endüstri Mühendisliğ Dergisi, 11(3), 2-10. Erişim adresi: docplayer.biz.tr/18931696-Cimento-sektorunde-g0reli-faaliyet-performanslarinin-agirlik-kisitlamalari-vecapraz-etkinlik-kullanilarak-veri-zarflama-analizi-ile-degerlendirilmesi.html.

Kirac1, K., \& Asker, V. (2019). Etkinlik ve etkinliği belirleyen faktörler: havayolu şirketleri üzerine ampirik bir inceleme. Eskişehir Osmangazi Üniversitesi İ̈BF Dergisi, 14(1), 25-50. https://doi.org/10.17153/oguiibf.408862

Lang, P., Yolalan, R. ve Kettani, O. (1995). Controlled envelopment by face extension. Journal of the Operational Research Society, 46(4), 473-491. doi.org/10.1057/jors.1995.66

Lee, B. ve Worthington, A. (2014). Technical efficiency of mainstream airlines and low-cost carriers: New evidence using bootstrap data envelopment analysis truncated regression. Journal of Air Transport Management, 38(3), 15-20. doi.org/10.1016/j.jairtraman.2013.12.013

Lin, Y.-H. L. ve Hong, C.-F. (2019). Efficiency and effectiveness of airline companies in Taiwan and Mainland China. Asia Pacific Management Review, 24(3), 1-10. doi.org/10.1016/j.apmrv.2019.04.002

Lorcu, F. (2008). Veri zarflama analizi (dea) ile türkiye ve avrupa birliği ülkelerinin sağhk alanndaki etkinliklerinin değerlendirilmesi (Dokotra Tezi). İstanbul Üniversitesi Sosyal Bilimler Enstitüsü, İstanbul.

Lu, W.-M., Wang, W.-K., Hung, S.-W. ve Lu, E.-T. (2012). The effects of corporate governance on airline performance: Production and marketing efficiency perspectives. Transportation Research Part E, 48(2), 529-544. doi.org/10.1016/j.tre.2011.09.003

Omrani, H. ve Soltanzadeh, E. (2016). Dynamic DEA models with network structure: An application for Iranian airlines. Journal of Air Transport Management, 57(4), 52-61. doi.org/10.1016/j.jairtraman.2016.07.014

Pourjavad, E. ve Shirouyehzad, H. (2014). A data envelopment analysis approach for measuring the efficiency in continuous manufacturing lines: a case study. International Journal of Services and Operations Management, 18(2), 142158. Do1: 10.1504/IJSOM.2014.061998

Ramanathan, R. (2003). An introduction to data envelopment analysis a tool for performance measurement. New Delhi: Sage Publications. 
Saranga, Haritha; Nagpal, Rajiv (2016), Drivers of Operational Efficiency and its Impact on Market Performance in The Indian Airline Industry. Journal of Air Transport Management, 53(4), 165-176. https://doi.org/10.1016/j.jairtraman.2016.03.001

Schefczyk, M. (1993). Operational Performance of Airlines: An extension of Traditional Measurment Paradigms. Strategic Management Journal, 14(4), 301-317. doi.org/10.1002/smj.4250140406

Scheraga, C. A. (2004). Operational efficiency versus financial mobility in the global airline industry: a data envelopment and Tobit analysis. Transportation Research Part A, 38(5), 383-404. doi.org/10.1016/j.tra.2003.12.003

Wang, W.-K., Lu, W.-M. ve Tsai, C.-J. (2011). The relationship between airline performance and corporate governance amongst US Listed companies. Journal of Air Transport Management, 17(2), 148-152. doi.org/10.1016/j.jairtraman.2010.06.005

Weng, S. J., Wu, T., Blackhurst, J. ve Mackulak, G. (2009). An extended DEA model for hospital performance evaluation and improvement. Health Service Outcomes Research Method, 39(1), 39-53. Do1: 10.1007/s10742-0080042

Yolalan, R. (1993). İşletmelerarası Göreli Etkinlik Ölçümü. Ankara: Milli Prodüktivite Merkezi Yayınları.

Yu, H., Zhang, Y., Zhang, A., Wang, K. ve Cui, Q. (2019). A comparative study of airline efficiency in China and India: A dynamic network DEA approach. Research in Transportation Economics, 76(4), 1-12. doi.org/10.1016/j.retrec.2019.100746

Yu, M.-M., Chen, L.-H. ve Chiang, H. (2017). The effects of alliances and size on airlines dynamic operational performance. Transportation Research Part A, 106(5), 197-214. doi.org/10.1016/j.tra.2017.09.015

Zhu, J. (2011). Airlines Performance via Two-Stage Network DEA Approach. Journal of CENTRUM Cathedra, 4(2), 260-269. Erişim adresi: https://papers.ssrn.com/sol3/papers.cfm?abstract_id=1931862

\section{EXTENDED ABSTRACT}

With the liberalization movement in the air transport sector in recent years, it has been observed that the air transport sector has grown rapidly and the number of companies operating in the sector has increased. This situation has turned the air transport sector into a sector where competition is more intense. In this sector, where there is intense competition, companies have had to develop various strategies in order to continue their current activities, increase their shares in the markets, and ensure the balance of income and expenses.

Operational and financial efficiency measurement has a very important place in the air transport sector, where profitability is low and costs are high, there is sudden fluctuations in demand, competition is more stronger, technological change and transformation are more common, and operational and financial activities affect each other more. The aim of this study is to compare the operational and financial efficiency of airline companies operating in various parts of the world and applying different business models. In the literature, it has been determined that the number of studies in which the efficiency measurement has been carried out by two-stage data envelopment analysis, both in operational and financial terms, by classifying airline companies according to the business model they have applied, is quite low. In this respect, it is thought that this study will contribute to the literature with this aspect.

In this study, the operational and financial efficiency measurement of a total of 36 airline companies, which fly to many parts of the world and apply different business models, was carried out through a twostage data envelopment analysis. In this respect, the financial efficiency of the airline companies was measured in the first stage, and in the second stage, in order to determine the effect of operational efficiency on financial efficiency. In order to measure operational efficiency, the number of seat kilometer (ASK), number of aircraft and Number of Employees were evaluated as input variables, Number of Passengers, Revenue Passenger Kilometers (RPK) and load factor were evaluated as output variables. In the second stage of the analysis, in order to determine the effect of operational efficiency on financial efficiency, the efficiency scores obtained as a result of the operational efficiency measurement were included in the analysis as input variables, while the Net Profit / Net Sales ratio and the Net Profit / Total Assets ratio as output variables. Deap 2.1 software program was used in the efficiency measurement phase. Due to the operational and financial variables used in the study, it was decided to use the outputoriented data envelopment analysis model. CCR and BCC models, which are accepted as the basic model of data envelopment analysis, were used in the study.

As a result of the efficiency measurement performed with the data envelopment analysis in terms of operation, it has been observed that among the traditional airline companies, Air Canada, Avianca, Delta Airlines, Scandinavian Airlines and Skywest have been efficient throughout the entire period in terms of 
operation, and the China Southern business was not efficient during the entire period. It was found that Air China was not efficient only in 2014, and Latam Airlines and Qantas Airways were not efficient only in 2018. Japan Airlines was found to be efficient only in 2017. While it was observed that Air Arabia, Cebu Pacific Air, Lion Air and Wizz Air among the low-cost airline companies were efficient throughout the period, Gol Linhas, Jet Blue Airways, Spirit Airlines and Westjet were not efficient during the entire period.

As a result of the efficiency measurement made with financial data envelopment analysis, among the traditional airline companies, Aeroflot in 2016, Air Canada and Skywest in 2017, American Airlines in 2015, Delta Airlines in 2013 and 2016, Turkish Airlines in 2015 and United Continental in 2014 reached their efficiency limit. Financially low-cost airline companies included Air Arabia in 2013-2014, Air Asia in 2016, Allegiant in 2015, Ryanair in 2014-2015 and 2017-2018, Spirit Airlines in 2013 and Wizz Air in 2014 and 2016-2018 were found to be efficient.

As a result of the operational efficiency measurement of the data envelopment analysis with the output-oriented CCR and BCC model, it has been determined that the number of efficient company is 68\% among traditional airline companies and 58\% among the low cost airline companies. In this respect, it can be said that airline companies applying the traditional business model perform better in terms of operational efficiency compared to the airline companies applying the low-cost business model. In terms of financial efficiency, it has been determined that the number of active company is $12 \%$ among traditional airline companies and $21 \%$ among low-cost airline companies. In this respect, it can be said that low-cost airline companies are in a better position in terms of financial efficiency. In general, it has been observed that traditional and low-cost airline companies cannot turn their operational success into financial success.

Among the traditional and low-cost airline companies included in the analysis, 3 airline companies (Air Canada, Delta Airlines, Skywest) North America-based, 3 airline companies (Air Arabia, Cebu Pasific Air, Lion Air) Asia-based, 2 airline companies (Scandinavian Airlines, Wizz Air) is Europe-based and 1 airline company (Avianca) is based in South America. It has been observed that the number of companies engaged in long-haul flights is higher among businesses that are efficient in this respect.

When both operational and financial efficiency analysis of airline companies applying different business models are evaluated, it has been determined that different results have emerged for companies. It is believed that the results obtained in this context will contribute to the development of strategies to increase operational and financial efficiency by providing the managers of companies operating in the airline transport sector with the opportunity to analyze and evaluate these results. 